\title{
From stillness to motion: 80 years after the first description of Taenia solium oncosphere hatching
}

\author{
Fela Mendlovic ${ }^{1,2}$, Adriana Garza-Rodríguez ${ }^{3}$, Joaquin Carrillo-Farga ${ }^{4}$, Fernando González-Domínguez³, \\ Pablo Maravilla ${ }^{3}$ and Ana Flisser ${ }^{1^{*}}$
}

\begin{abstract}
Background: Human neurocysticercosis (NCC) is a considered public health problem in many underdeveloped and developing countries. Because of the enormous increase in international tourism and migration, NCC nowadays is also found in some developed countries. Our group was the first to demonstrate that tapeworm carriers in the household are the main risk factor for acquiring cysticercosis in humans and pigs, since the disease results from the ingestion of microscopic tapeworm eggs.
\end{abstract}

Findings: We had the opportunity to film the liberation of the embryo from the oncospheral membrane after the hatching of the egg, which is the activation process required for intestinal wall invasion by the onchosphere. Yoshino (J Formosa Med Ass 32:139-142, 1933) described with great detail in diagrams and photographs this process eighty years ago after he infected himself with three living cysticerci in order to study the life cycle of Taenia solium. Other authors further described this process. Nevertheless it has never been filmed before. The purpose of this paper is to shift from stillness to motion since we can now show for the first time a movie of an activated oncosphere and its release from the oncospheral membrane.

Conclusion: Oncospheral activation is the requisite for T. solium embryos to invade the intestinal mucosa and develop into cysticerci. This process has been amply described but here it is shown for the first time in motion; thus it may be of interest for readers of the journal and useful for educational purposes towards the control of NCC.

Keywords: Activation, Cysticercosis, Hatching, Humans, Neurocysticercosis, Oncospheres, Pigs, Taenia solium, Video

\section{Findings}

The life cycle of $T$. solium includes the human being as the definitive host that harbors the intestinal tapeworm and the pig as the intermediate host in which the larval stage or cysticercus develops. Definitive hosts acquire the disease after ingesting undercooked infected pork meat, while cysticercosis is produced after swine consume infected human feces that contain tapeworm gravid proglottids full of eggs. In addition, accidental ingestion of these eggs can cause human neurocysticercosis (NCC), a public health problem in many developing countries and an emerging infectious disease in some developed ones [1-3]. NCC is a neglected tropical disease that is underfinanced and caused 25,341 disability

\footnotetext{
*Correspondence: flisser@unam.mx

${ }^{1}$ Facultad de Medicina, Universidad Nacional Autónoma de México, México 04510 DF, Mexico

Full list of author information is available at the end of the article
}

adjusted life years (DALYs) in Mexico during 2005 due to epilepsy $(90 \%)$ and severe chronic headaches (10\%) associated to NCC [4]. Improvements in research, diagnosis, treatment and control have been achieved in Mexico, suggesting that NCC may no longer be a public health problem in this country [5]. This approach should be taken into consideration for the control of zoonoses and marginalized infectious diseases of poverty recently reviewed [6].

Our group was the first to demonstrate that patients with NCC are found mainly where a tapeworm carrier is part of the household [7], thus the egg is one of the main targets for the control of NCC. The morphology of tapeworm eggs has been described and illustrated in photographs and diagrams as early as 1933 by Yoshino [8], and afterwards by other authors [9-13]. Eggs measure between 26 and $34 \mu \mathrm{m}$ and have a radial appearance

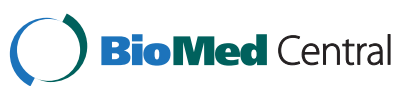

(c) 2014 Mendlovic et al.; licensee BioMed Central Ltd. This is an Open Access article distributed under the terms of the Creative Commons Attribution License (http://creativecommons.org/licenses/by/2.0), which permits unrestricted use, distribution, and reproduction in any medium, provided the original work is properly cited. The Creative Commons Public Domain Dedication waiver (http://creativecommons.org/publicdomain/zero/1.0/) applies to the data made available in this article, unless otherwise stated. 


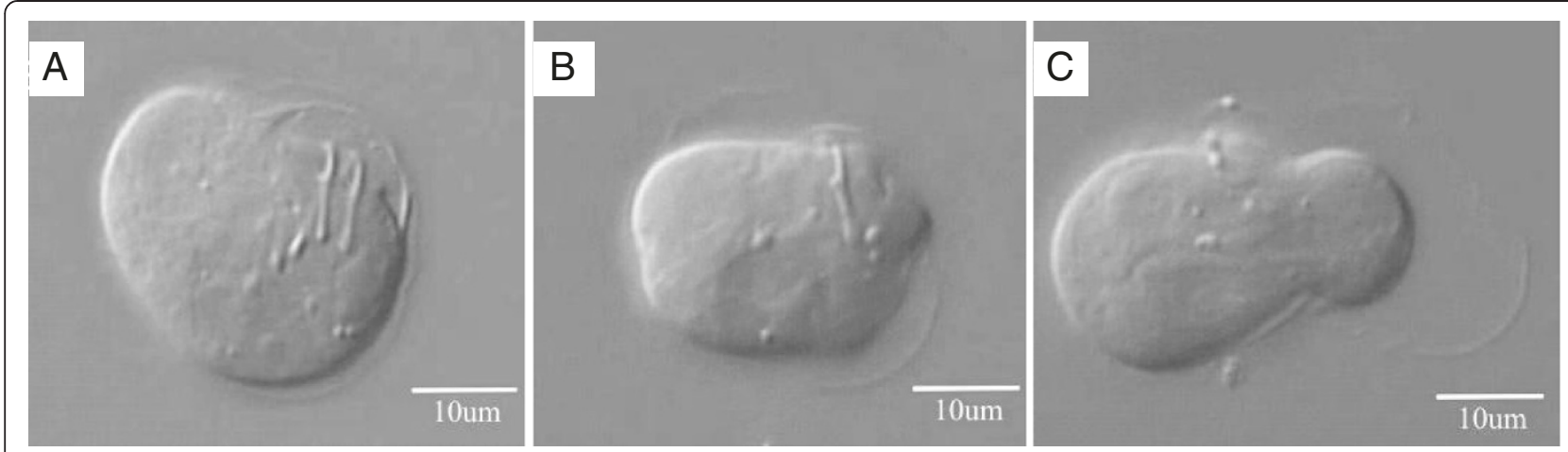

Figure 1 Activation process of a Taenia solium oncosphere. At the beginning of the activation process, an oncosphere completely surrounded by the oncospheral membrane is seen (A). With time, the oncospheral membrane is detached and seen above and below the oncosphere (B). At the end, the hexacanth is seen almost completely out of the oncospheral membrane, which remains, at the right side (C). Hooks are evident in (A) and (B).

because of the embryophore that surrounds and protects the oncosphere that is covered by the oncospheral membrane.

After ingesting eggs, hexacanths must be released from their envelopes and penetrate the intestinal mucosa. Yoshino described the conditions for the hatching and activation of $T$. solium eggs after he infected himself with three live cysticerci to study the life cycle of Taenia solium. Disaggregation of the embryophore is known as hatching, while liberation from the oncospheral membrane is the activation process that take place in the presence of bile salts. Now, 80 years later, we had the opportunity to film the liberation of the hexacanth from the oncospheral membrane (film enclosed). By shifting from stillness to motion we show, for the first time, a movie filmed under an optic microscope (AX70 Olympus microscope with a Carl Zeiss camera attachment) of an oncosphere in the process of activation, as it liberates itself from the oncospheral membrane. Eggs were treated as described by Kyngdon et al. [13]. At the beginning of the film the oncosphere is seen after hatching, still surrounded by the oncospheral membrane, body movements are slow and increase in frequency as time elapses. Hooks also start moving and the structure of the hook described by Yoshino [8], as a stem with a terminal sickle-shaped portion, can be seen (Additional file 1: Movie S1 and Figure 1A and B). One minute after the beginning of the movie, a hook in the center of the embryo is seen seemingly scratching the inside of the oncospheral membrane. The oncosphere contracts and expands escaping from the membrane, probably through a hole, since a constriction around the embryo is evident. The hexacanth emerges towards the left side of the movie leaving the membrane behind (Additional file 1: Movie S1 and Figure 1C). The overall process of filming was speeded-up 5 times.
Oncospheral activation is the requisite for $T$. solium embryos to invade the intestinal mucosa and develop into cysticerci. This process has been amply described but here it is shown for the first time in motion, thus it may be of interest for readers of the journal and useful for educational purposes towards the control of NCC.

\section{Additional file}

Additional file 1: Movie S1. The movie was filmed under an optic microscope and speeded-up 5 times. It shows the activation of a Taenia solium oncosphere.

\section{Competing interests}

The authors declare that they have no competing interests.

\section{Authors' contributions}

AGR and PM obtained and activated onchospheres. JCF, FGD, FM and AF participated in the filming process. FM and AF wrote the manuscript. All authors read and approved the final version of the manuscript.

\section{Author details}

${ }^{1}$ Facultad de Medicina, Universidad Nacional Autónoma de México, México 04510 DF, Mexico. ${ }^{2}$ Facultad de Ciencias de la Salud, Universidad Anáhuac del Norte, México Norte, Av. Universidad Anáhuac 46, Huixquilucan Estado de México 52786, Mexico. ${ }^{3}$ Dirección de Investigación, Hospital General "Dr. Manuel Gea González" SSA, México 14000 DF, Mexico. ${ }^{4}$ Instituto de Hematopatología, Tamaulipas 131, Col. Cuajimalpa, México 05000 DF, Mexico.

Received: 25 November 2013 Accepted: 27 November 2013 Published: 16 January 2014

\section{References}

1. Schantz PMWP, Tsang VCW: Immigrants, imaging and immunoblots: the emergence of neurocysticercosis as a significant public health problem. In Scheld WM et al., eds. Emerging Infections 2. pp 213-242. Washington, DC: AMS Press; 1998.

2. Coyle CM, Mahanty S, Zunt JR, Wallin MT, Cantey PT, White AC Jr, O'Neal SE, Serpa JA, Southern PM, Wilkins P, et al: Neurocysticercosis: neglected but not forgotten. PLoS Neg Trop Dis 2012, 6(5):e1500.

3. Yanagida T, Sako Y, Nakao M, Nakaya K, Ito A: Taeniasis and cysticercosis due to Taenia solium in Japan. Parasites Vectors 2012, 5:18. 
4. Bhattarai R, Budke CM, Carabin H, Proano JV, Flores-Rivera J, Corona T, Ivanek R, Snowden KF, Flisser A: Estimating the non-monetary burden of neurocysticercosis in Mexico. PLoS Neg Trop Dis 2012, 6(2):e1521.

5. Flisser A, Correa D: Neurocysticercosis may no longer be a public health problem in Mexico. PloS Neg Trop Dis 2010, 4(12):e831.

6. Molyneux D, Hallaj Z, Keusch GT, McManus DP, Ngowi H, Cleaveland S, Ramos-Jimenez P, Gotuzzo E, Kar K, Sanchez A, et al: Zoonoses and marginalised infectious diseases of poverty: where do we stand? Parasites Vectors 2011, 4:106.

7. Sarti-Gutierrez EJ, Schantz PM, Lara-Aguilera R, Gomez Dandoy H, Flisser A: Taenia solium taeniasis and cysticercosis in a Mexican village. Trop Med Parasitol 1988, 39(3):194-198.

8. Yoshino K: Studies on the post-embryonal development of Taenia solium I. On the hatching of the eggs of Taenia solium. J Formosa Med Ass 1933, 32:139-142.

9. Laclette JP OY, Merchant MT, Willms K: Ultrastructure of the surrounding envelopes of Taenia solium eggs. In Cysticercosis. Present state of knowledge and perspectives. Edited by Flisser, et al. New York: Academic Press; 1982:375-387.

10. Wang IC, Ma YX, Kuo CH, Fan PC: A comparative study on egg hatching methods and oncosphere viability determination for Taenia solium eggs. Int J Parasitol 1997, 27(11):1311-1314.

11. Pawlowski Z: Taenia solium. Basic biology and transmission. In Taenia solium cysticercosis. From basic to clinical science. Edited by Singh $\mathrm{G}$, Prabhakar S. Oxon, UK: CABI Publ; 2002:1-13.

12. Flisser A, Correa D, Avila G, Maravilla P: Biology of Taenia solium. In Taenia saginata and Taenia saginata asiatica. Edited by Murrell KD. en: WHO/FAO/ OIE Guidelines for the surveillance, prevention and control of taeniosis/ cysticercosis; 2005:1-9.

13. Kyngdon CT, Gauci CG, Rolfe RA, Velasquez Guzman JC, Farfan Salazar MJ, Verastegui Pimentel MR, Gonzalez AE, Garcia HH, Gilmanl RH, Strugnell RA, et al: In vitro oncosphere-killing assays to determine immunity to the larvae of Taenia pisiformis, Taenia ovis, Taenia saginata, and Taenia solium. J Parasitol 2006, 92(2):273-281.

doi:10.1186/1756-3305-7-12

Cite this article as: Mendlovic et al.: From stillness to motion: 80 years after the first description of Taenia solium oncosphere hatching. Parasites \& Vectors 2014 7:12.

\section{Submit your next manuscript to BioMed Central and take full advantage of:}

- Convenient online submission

- Thorough peer review

- No space constraints or color figure charges

- Immediate publication on acceptance

- Inclusion in PubMed, CAS, Scopus and Google Scholar

- Research which is freely available for redistribution 